\title{
THE IMPACT OF CHINESE E-GOVERNMENT-TO-CITIZENS ON GOVERNMENT TRANSPARENCY AND PUBLIC PARTICIPATION
}

\author{
Dr. Jensen J. Zhao, Ball State University,jzhao@bsu.edu \\ Dr. SherryY. Zhao, Massachusetts Institute of Technology, syzhao@alum.mit.edu \\ Dr. MelodyW. Alexander, Ball State University, malexand@bsu.edu \\ Dr. Allen D. Truell, Ball State University, atruell@bsu.edu
}

\begin{abstract}
China has the largest population of Internet users in the world. On average, every Chinese user spent 25 hours per week on the Internet. However, no empirical study has been documented in the literature to investigate the impact of e-government-to-citizens (eG2C) services on government transparency and public participation in China. This study assessed how the Chinese eG2C services affect government transparency and citizens' participation via the Web analytics of 31 Chinese province official eG2C sites. The findings indicate that most of the province eG2C links were convenient for citizens to identify on the e-government sites. The majority of the eG2C sites provided citizens with 19 online services but the majority of them were mainly for information sharing, search, and downloading. Only a minority of them offered transactional and intelligent capacities enabling citizens to do business online such as filing tax documents, renewing licenses, creating and managing online accounts.
\end{abstract}

Keywords: E-Government-To-Citizens, Government Transparency, Public Participation, Functional Capacity, User-Interface Effectiveness

\section{INTRODUCTION}

The advancement of Internet technologies have empowered the grassroots people to engage in democracy campaigns around the globe. While the totalitarian governments view the Internet as a big threat to their regimes, the democratic governments consider the Internet as an opportunity for better engaging their people in government affairs. For instance, on January 21, 2009, the U.S. President Barack Obama issued a memorandum calling for the establishment of a system to promote the government commitments to transparency, public participation and collaboration. To engage the public, the U.S. Federal agencies are increasingly using Internet-based technologies, such as Web services, blogs, wikis, and social networks, as a means for presenting solicitations for public comment and for conducting virtual public meetings [9].

Similarly, on February 27, 2014, the Chinese President Xi Jinping stressed at the first meeting of China's Central Network Security and Informationization Leading Group that the Internet security and information technology are important strategic issues that impact not only a nation's security and development but also its people's daily work and life. Therefore, China must plan strategically, coordinate all the areas, promote innovation and advancement, and make efforts to build China into a powerful, networked country [11].

According to the January 2014 Statistical Report of China Internet Network Development Status [6], at the end of 2013, Chinese Internet users reached 618 million, which was $45.8 \%$ of China's total population. On average, every user spent 25 hours per week on the Internet for business, entertainment, news, school, shopping, social and cultural activities, etc. Research also indicated that contrary to the previous understandings of the Chinese government control of the Internet, posts with negative, even vitriolic, criticism of the state, its leaders, and its policies were not more likely to be censored. Instead, in order to keep social order and stability, the Internet censorship was aimed at curtailing collective activities that were occurring or might occur by silencing comments that represent, reinforce, or spur social mobilization [8]. To engage citizens for participation in anti-corruption and government transparency, Chinese central and province government-to-citizens (eG2C) sites provided services such as email to top officials, suggestion and complaint box, and report fraud box for citizens' communication and participation in government administration and policies. For example, the eG2C site of the China Ministry of Supervision started the report fraud box on September 2, 2013, and by September 21, 2013, it received 15,253 reports from citizens regarding 
government officials' corruption, bribery, negligence, malfeasance, or other violations of law [4].

China now is the second-largest economy of the world and had 618 million Internet users by the end of 2013. However, no empirical study has been documented in the literature to investigate the impact of eG2C services on government transparency and public participation in China. This research gap suggests a need for an empirical study.

\section{PROBLEM AND PURPOSE OF THE STUDY}

The problem addressed in this study was to assess how the Chinese province eG2C services affect government transparency and citizens' participation. In order to solve the problem, we raised the following four research questions:

1. What eG2C services are available for promoting government transparency and citizens' participation?

2. How do eG2C services enable citizens to do business online, communicate views, and participate in government decisions?

3. Are there any significant differences of eG2C services between affluent provinces and less affluent provinces?

The primary purpose of the study is to advance the global knowledge base of the eG2C development in the egovernment discipline by including the findings from China, which is has the largest population of Internet users. Second, the findings of the study would serve as benchmarks for e-government administrators and developers to continuously improve their eG2C services as a means to government transparency and public participation. Finally, the findings would enable educators to update their curriculum by including comparative studies of government and public use of the Internet among different countries and adding effective ways of using eG2C services so that students will be able to choose proper media to meet their online communication and participation needs.

\section{RESEARCH METHODS}

Web content analysis and focus interviews were used to collect data and answer the research questions of this study. Web content analysis is commonly used in assessing organizations' strategies, deliveries, and interactions to customers, employees, investors, and other stakeholders on their Web sites [e.g., 2, 3, 10, 13, \& 14]. To systematically and objectively record what eG2C services were available in China, an instrument was developed based on the review of related literature [e.g., 1, 2, 6, 8, 10, 12, \& 14].

The instrument for assessing Chinese eG2C services consisted of (a) user-interface design such as homepage, languages, content, graphics, navigation convenience, and hyperlink locations; (b) types and capacities of eG2C services and their effectiveness; and (c) types and capacities of communication tools available on eG2C services. The functional capacity of each eG2C service was ranked on the basis of four evolutional phases of Web site sophistication and functionality: (1) informational = allowing users to get information only; (2) interactive = enabling users to get or search for information, download forms, and send email; (3) transactional = allowing users to do business online such as filing tax documents, renewing licenses, and bidding contracts; and (4) intelligent = enabling users to create accounts and personalize the site contents and services [e.g., 14].

The user-interface effectiveness of each eG2C service was evaluated on a four-point scale with $1=$ not effective, $2=$ less effective, $3=$ effective, and $4=$ very effective. Operationally, a very effective eG2C service was defined as to meet $75 \%-100 \%$ of what a user needs from the service; effective = meeting $50 \%-74 \%$ of what a user needs from the service; less effective $=$ meeting $25 \%-49 \%$ of what a user needs from the service; and not effective $=$ meeting $0 \%-24 \%$ of what a user needs from the service. The content validity of the instrument was tested by a threemember panel of Web design faculty who had at least five years of teaching, research, and consulting experience with Web design and development for e-business. Panel members agreed that the instrument items addressed issues stated in the problems of the study. The measurement reliability of the instrument was tested by two researchers who have good command of Chinese and English and are also very familiar with Chinese politics, cultures, and society. After a short training session on how to assess the Chinese eG2C and social media appropriately, the two raters were assigned to three pilot Chinese e-government sites for the content analysis. The raters worked independently on each site but the same time for Web content consistency. After completing the three pilot sites, an inter-rater correlation coefficient of $98.6 \%$ was identified at the .05 significance level. 
The population of the study was the official e-government sites at the province level. The People's Republic of China consists of 22 provinces, 5 autonomous regions, 4 direct-controlled municipalities (Beijing, Tianjin, Shanghai, and Chongqing), and 2 mostly self-governing special administrative regions (Hong Kong and Macau). Since Hong Kong and Macau are self-governing special administrative regions, they were not included in this study. Therefore, the study included all 31 e-government sites of the 22 provinces, 5 autonomous regions, and 4 direct-controlled municipalities according to the requirement for sample size [7].

All the data from Web content analysis and focus interviews were collected in January through April 2014 and then coded for analysis. Frequency counts, percentage distributions, means, and standard deviations were prepared. The independent t-test was employed to identify if any significant difference existed between economically affluent provinces and less affluent ones in administering and promoting eG2C and social media services for government transparency and public participation. This was done because previous research reported that economically affluent counties offered better e-government sites than did the less affluent ones [10]. In this study, affluent provinces were operationally defined as provinces with the Chinese DLI (Development and Life Index) above or equal to the national median and less affluent ones referred to provinces with DLI below the national median. Developed on the basis of United Nations' Human Development Index (HDI), the Chinese DLI is used by the China National Statistics Bureau to measure economic development, life improvement, societal development, ecological construction, and science and technology innovation of provinces and regions [5].

\section{FINDINGS}

Research Question 1 asked, "What eG2C services are available for promoting government transparency and citizens' participation?" As Table 1 presents, the majority (90\%) of the 31 eG2C links were very convenient or convenient for citizens to identify when they visit the e-government sites, whereas only three sites $(10 \%)$ were rated as "less convenient" to identify the eG2C service pages. When users clicked on eG2C links, $97 \%$ of the eG2C main pages appeared on screen around one second and $77 \%$ of the G2C main pages were presented within approximately one screen. The majority $(65 \%)$ of the graphic illustrations on the eG2C main pages were local historical or scenery attractions, followed by province logos $(23 \%)$.

To facilitate government transparency and citizens' use of e-government services, the majority of the 31 eG2C sites provided the following 19 services online: birth planning/adoption (97\%), employment (97\%), healthcare (97\%), citizenship registration (94\%), marriage license (94\%), education (94\%), customs/immigration (90\%), social security $(90 \%)$, housing $(87 \%)$, transportation (84\%), culture/religion (74\%), passport/licenses (74\%), public/postal services (71\%), individual tax and reporting (71\%), death and funeral (68\%), military service (65\%), legal service (58\%), travel (58\%), and disability (52\%). However, only $12 \mathrm{eG} 2 \mathrm{C}$ sites (39\%) offered online service for residents of Hong Kong, Macao, Taiwan, and overseas Chinese. Regarding the availability of communication tools on province eG2C sites, only five tools were available, with email taking the lead on $97 \%$ of the 31 eG2C sites, followed by report fraud box (94\%), suggestion/complaint Box (94\%), mobile Web service (39\%), and Weibo (a Chinese Twitter-like tool, 29\%).

Research Question 2 asked, "How do eG2C services enable citizens to do business online, communicate views, and participate in government decisions?" The following eight types of eG2C services were available on the majority of the 31 sites: birth planning/adoption, employment, healthcare, citizenship registration, marriage license, education, customs/immigration, and social security. The functional capacity measures of eG2C services indicated that these eight popular types of eG2C services provided a range of informational, interactive, transactional, and intelligent capacities (see Figure 1). However, as the line chart in Figure 1 illustrates, the availability of the eight eG2C services declined continually in capacities. While $90 \%$ to $97 \%$ of the 31 sites provided these services at the informational phase, only $42 \%$ to $61 \%$ of the sites offered the same eight services at the interactive phase enabling citizens to get or search for information, to download forms, and to send email. The availability was again declined to $29 \%$ to $55 \%$ of the sites providing the same eight services at the transactional phase allowing users to do business online such as filing tax documents, renewing licenses, and bidding contracts. A further smaller number of sites (13\% to $35 \%$ ) offered the same eight services at the advanced intelligent phase enabling citizens to create their accounts and personalize the site contents and services. The other 12 less-available eG2C services were mainly at the informational and interactive phases, with just few having transactional and intelligent capacities.

The user-interface effectiveness of eG2C services were evaluated on a four-point scale with $1.0 \sim 1.4=$ not effective, 
1.5 2.4 = less effective, 2.5 3.4 = effective, and 3.5 4.0 = very effective. As the weighted means in Figure 2 shows, all the following eight popular eG2C services were rated as effective to online users at the four different phases: birth planning/adoption, employment, healthcare, citizenship registration, marriage license, education, customs/immigration, and social security. Among them, only healthcare, education, marriage license, and social security were also rated as very effective at the transactional or intelligent phases. While the 12 less-available eG2C services were mainly at the informational and interactive phases, with just few having transactional and intelligent capacities, these eG2C services were also rated as effective to use when available.

Table 1: Characteristics of Province E-Government-to-Citizens Services Main Pages ( $\mathrm{N}=31)$

\begin{tabular}{|c|c|c|}
\hline Characteristics & Frequency & Percent \\
\hline \multicolumn{3}{|l|}{ Convenience of Identifying G2C Page: } \\
\hline Very Convenient & 20 & $64 \%$ \\
\hline Convenient & 8 & $26 \%$ \\
\hline Less Convenient & 3 & $10 \%$ \\
\hline G2C Main Page Loading Time $\approx 1$ Second & 30 & $97 \%$ \\
\hline G2C Main Page Length $\approx 1$ Screen & 24 & $77 \%$ \\
\hline \multicolumn{3}{|l|}{ Graphic Illustrations on Main Page: } \\
\hline Attractions & 20 & $65 \%$ \\
\hline Province Logo & 7 & $23 \%$ \\
\hline Other Graphics & 3 & $10 \%$ \\
\hline \multicolumn{3}{|l|}{ eG2C Services: } \\
\hline Birth Planning/Adoption & 30 & $97 \%$ \\
\hline Employment & 30 & $97 \%$ \\
\hline Healthcare & 30 & $97 \%$ \\
\hline Citizenship Registration & 29 & $94 \%$ \\
\hline Marriage License & 29 & $94 \%$ \\
\hline Education & 29 & $94 \%$ \\
\hline Customs/Immigration & 28 & $90 \%$ \\
\hline Social Security & 28 & $90 \%$ \\
\hline Housing & 27 & $87 \%$ \\
\hline Transportation & 26 & $84 \%$ \\
\hline Culture/Religion & 23 & $74 \%$ \\
\hline Passport/Licenses & 23 & $74 \%$ \\
\hline Public/Postal Service & 22 & $71 \%$ \\
\hline Individual Tax and Reporting & 22 & $71 \%$ \\
\hline Death and Funeral & 21 & $68 \%$ \\
\hline Military Service & 20 & $65 \%$ \\
\hline Legal Service & 18 & $58 \%$ \\
\hline Travel & 18 & $58 \%$ \\
\hline Disability & 16 & $52 \%$ \\
\hline Residents of HK/Macao//Taiwan/Overseas & 12 & $39 \%$ \\
\hline \multicolumn{3}{|l|}{ Communication Tools Available on eG2B Sites: } \\
\hline Email & 30 & $97 \%$ \\
\hline Report Fraud Box & 29 & $94 \%$ \\
\hline Suggestion/Complaint Box & 29 & $94 \%$ \\
\hline Mobile Web Service & 12 & $39 \%$ \\
\hline Weibo (Chinese twitter) & 9 & $29 \%$ \\
\hline
\end{tabular}




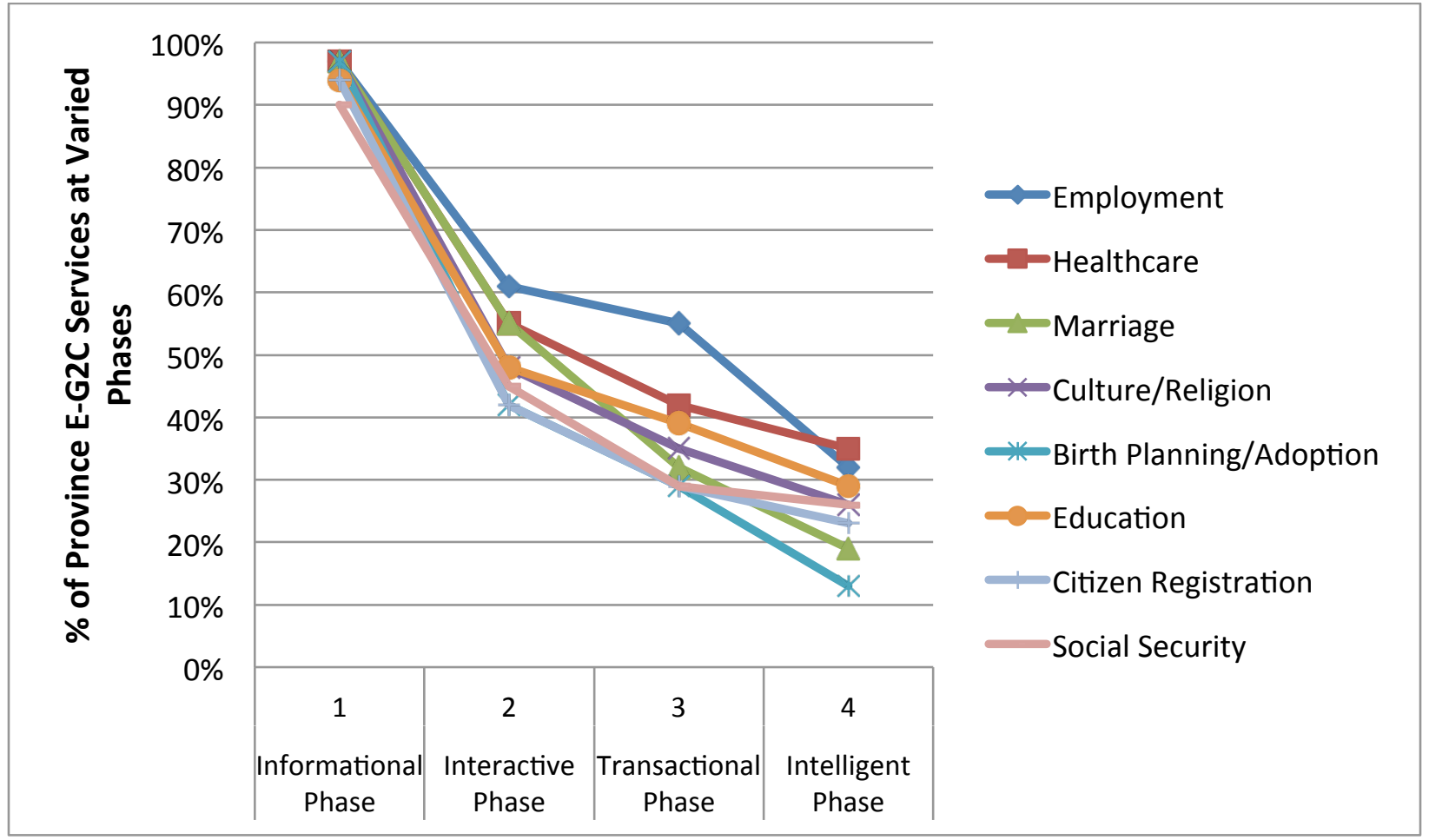

Figure 1. Status of Eight Most Popular Province eG2C Services at Four Different Phases $(\mathrm{N}=31)$

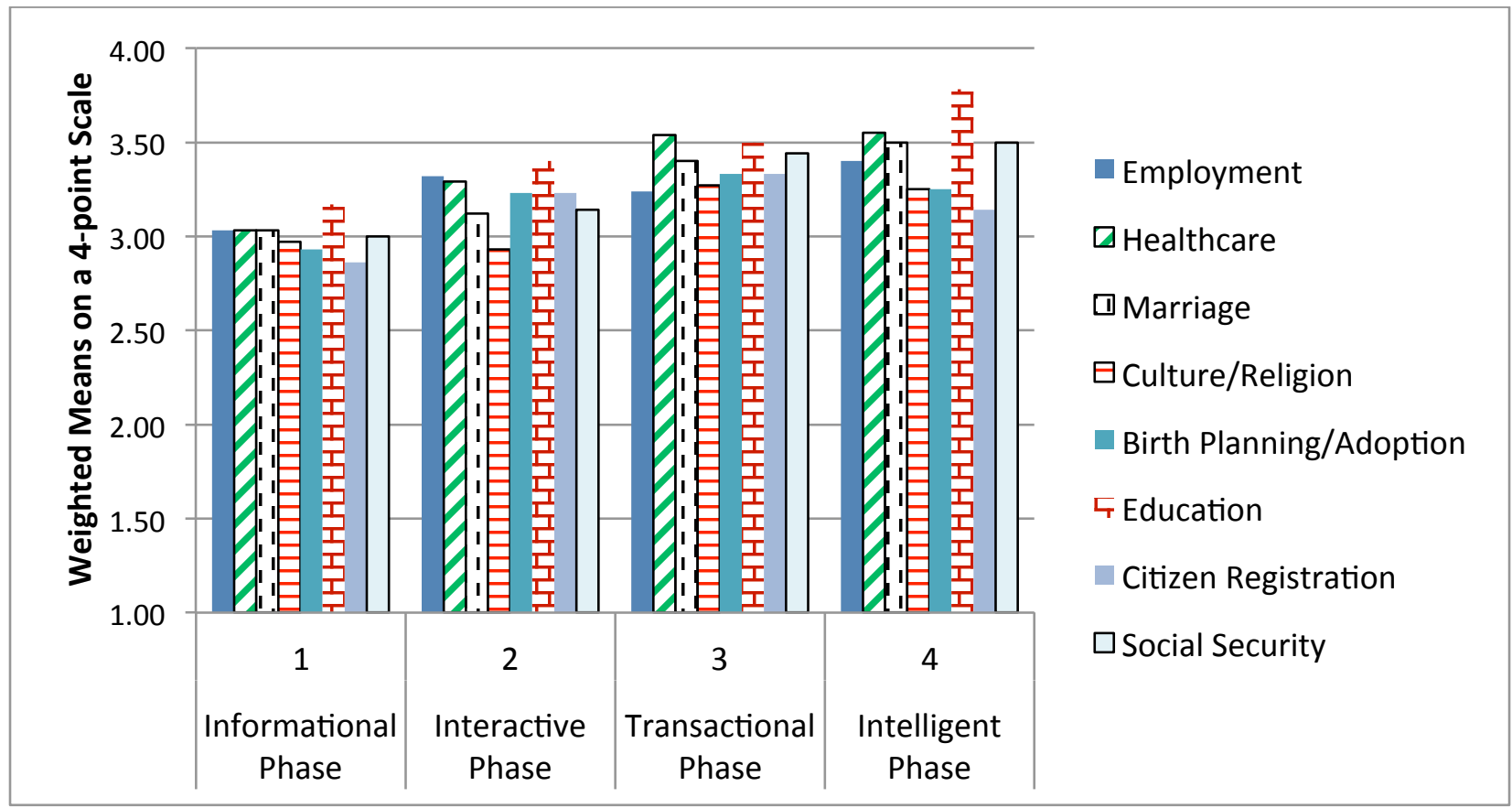

Figure 2. Effectiveness of Eight Most Popular Province eG2C Services at Four Different Phases $(\mathrm{N}=31)$

Research Question 3 asked, “Are there any significant differences of eG2C services between affluent provinces and less affluent provinces?" Table 2 shows that significant differences existed between affluent provinces and less 
affluent ones in 14 eG2C services at the informational, interactive, transactional, and intelligent phases. These 14 eG2C services consisted of birth planning/adoption, citizenship registration, culture/religion, customs/immigration, death/funeral, education, employment, healthcare, legal service, marriage license, passport/licenses, social security, individual tax and reporting, and transportation. As the scores of the independent t-test in Table 2 illustrate, the significant differences existed mainly at the interactive, transactional, and intelligent phases of the 14 eG2C services. The affluent provinces offered these $14 \mathrm{eG} 2 \mathrm{C}$ services at significantly more advanced levels than did the less affluent provinces.

Table 2: Independent T-Test on Province eG2C Services by High- and Low-HDI Groups ( $\mathrm{N}=31)$

\begin{tabular}{|c|c|c|c|c|c|c|c|}
\hline \multirow[b]{2}{*}{ Category } & \multirow{2}{*}{$\begin{array}{c}\text { Group } \\
1= \\
\text { affluent } \\
2=\text { less } \\
\text { affluent }\end{array}$} & \multirow[b]{2}{*}{$\mathbf{n}$} & \multirow[b]{2}{*}{ Mean } & \multirow[b]{2}{*}{$\begin{array}{c}\text { Std. } \\
\text { Deviation }\end{array}$} & \multicolumn{3}{|c|}{ T-Test of Means } \\
\hline & & & & & $\mathbf{t}$ & df & $\begin{array}{l}\text { Sig. (2- } \\
\text { tailed) }\end{array}$ \\
\hline \multirow[t]{2}{*}{ 1. Birth Planning at Transaction } & 1 & 16 & 1.688 & 1.7783 & 2.983 & 29 & .006 \\
\hline & 2 & 15 & .200 & .7746 & & & \\
\hline \multirow{2}{*}{ Birth Planning at Intelligent } & 1 & 16 & .813 & 1.4705 & 2.138 & 29 & .041 \\
\hline & 2 & 15 & 0.000 & 0.0000 & & & \\
\hline \multirow[t]{2}{*}{ 2. Citizen Registration at Info. } & 1 & 16 & 3.125 & .8062 & 2.524 & 29 & .017 \\
\hline & 2 & 15 & 2.200 & 1.2071 & & & \\
\hline \multirow[t]{2}{*}{ Citizen Registration at Interac. } & 1 & 16 & 1.938 & 1.8062 & 2.128 & 29 & .042 \\
\hline & 2 & 15 & .733 & 1.2799 & & & \\
\hline \multirow[t]{2}{*}{ Citizen Regis. at Transaction } & 1 & 16 & 1.688 & 1.7783 & 2.983 & 29 & .006 \\
\hline & 2 & 15 & .200 & .7746 & & & \\
\hline \multirow[t]{2}{*}{ Citizen Regis. at Intelligent } & 1 & 16 & 1.313 & 1.7783 & 2.684 & 29 & .012 \\
\hline & 2 & 15 & .067 & .2582 & & & \\
\hline \multirow{2}{*}{ 3. Culture/Religion at Transaction } & 1 & 16 & 1.813 & 1.6820 & 4.169 & 29 & .000 \\
\hline & 2 & 15 & 0.000 & 0.0000 & & & \\
\hline \multirow[t]{2}{*}{ Culture/Religion at Intelligent } & 1 & 16 & .875 & 1.5864 & 2.134 & 29 & .041 \\
\hline & 2 & 15 & 0.000 & 0.0000 & & & \\
\hline \multirow[t]{2}{*}{ 4. Customs/Immigration at Trans. } & 1 & 16 & 1.875 & 1.7464 & 2.822 & 29 & .009 \\
\hline & 2 & 15 & .400 & 1.0556 & & & \\
\hline \multirow[t]{2}{*}{ Customs/Immigration at Intell. } & 1 & 16 & 1.438 & 1.7115 & 2.563 & 29 & .016 \\
\hline & 2 & 15 & .200 & .7746 & & & \\
\hline \multirow[t]{2}{*}{ 5. Death/Funeral at Interactive } & 1 & 16 & 1.250 & 1.6931 & 2.194 & 29 & .036 \\
\hline & 2 & 15 & .200 & .7746 & & & \\
\hline \multirow[t]{2}{*}{ 6. $\quad$ Education at Interactive } & 1 & 16 & 2.625 & 1.6279 & 3.874 & 29 & .001 \\
\hline & 2 & 15 & .600 & 1.2421 & & & \\
\hline \multirow[t]{2}{*}{ Education at Transaction } & 1 & 16 & 2.438 & 1.7500 & 4.548 & 29 & .000 \\
\hline & 2 & 15 & .200 & .7746 & & & \\
\hline \multirow[t]{2}{*}{ Education at Intelligent } & 1 & 16 & 2.125 & 1.9621 & 4.190 & 29 & .000 \\
\hline & 2 & 15 & 0.000 & 0.0000 & & & \\
\hline \multirow[t]{2}{*}{ 7. Employment at Interactive } & 1 & 16 & 2.625 & 1.668 & 2.115 & 29 & .043 \\
\hline & 2 & 15 & 1.400 & 1.549 & & & \\
\hline \multirow{2}{*}{ Employment at Transaction } & 1 & 16 & 2.563 & 1.672 & 2.942 & 29 & .006 \\
\hline & 2 & 15 & .933 & 1.387 & & & \\
\hline \multirow[t]{2}{*}{ Employment at Intelligent } & 1 & 16 & 1.938 & 1.879 & 3.324 & 29 & .002 \\
\hline & 2 & 15 & .200 & 0.775 & & & \\
\hline
\end{tabular}




\begin{tabular}{|c|c|c|c|c|c|c|c|}
\hline \multirow[t]{2}{*}{ 8. Healthcare at Transaction } & 1 & 16 & 2.500 & 1.789 & 3.946 & 29 & .000 \\
\hline & 2 & 15 & .400 & 1.056 & & & \\
\hline \multirow{2}{*}{ Healthcare at Intelligent } & 1 & 16 & 2.250 & 1.844 & 3.986 & 29 & .000 \\
\hline & 2 & 15 & .200 & 0.775 & & & \\
\hline \multirow[t]{2}{*}{ 9. Legal Service at Interactive } & 1 & 16 & 1.563 & 1.632 & 2.572 & 29 & .015 \\
\hline & 2 & 15 & .333 & 0.900 & & & \\
\hline \multirow[t]{2}{*}{ Legal Service at Transaction } & 1 & 16 & 1.000 & 1.549 & 2.497 & 29 & .018 \\
\hline & 2 & 15 & 0.000 & 0.000 & & & \\
\hline \multirow[t]{2}{*}{ 10. Marriage at Transaction } & 1 & 16 & 1.750 & 1.844 & 2.479 & 29 & .019 \\
\hline & 2 & 15 & .400 & 1.056 & & & \\
\hline \multirow[t]{2}{*}{ Marriage at Intelligent } & 1 & 16 & 1.313 & 1.778 & 2.855 & 29 & .008 \\
\hline & 2 & 15 & 0.000 & 0.000 & & & \\
\hline \multirow[t]{2}{*}{ 11. Passport/Licenses at Interactive } & 1 & 16 & 2.188 & 1.559 & 3.122 & 29 & .004 \\
\hline & 2 & 15 & .600 & 1.242 & & & \\
\hline \multirow[t]{2}{*}{ Passport/Licenses at Transaction } & 1 & 16 & 2.125 & 1.544 & 3.017 & 29 & .005 \\
\hline & 2 & 15 & .600 & 1.242 & & & \\
\hline \multirow[t]{2}{*}{ Passport/Licenses at Intelligent } & 1 & 16 & 1.750 & 1.653 & 2.689 & 29 & .012 \\
\hline & 2 & 15 & .400 & 1.056 & & & \\
\hline \multirow[t]{2}{*}{ 12. Social Security at Interactive } & 1 & 16 & 2.125 & 1.746 & 2.668 & 29 & .012 \\
\hline & 2 & 15 & .667 & 1.234 & & & \\
\hline \multirow[t]{2}{*}{ Social Security at Transaction } & 1 & 16 & 1.750 & 1.844 & 3.013 & 29 & .005 \\
\hline & 2 & 15 & .200 & 0.775 & & & \\
\hline \multirow{2}{*}{ Social Security at Intelligent } & 1 & 16 & 1.563 & 1.861 & 2.628 & 29 & .014 \\
\hline & 2 & 15 & .200 & 0.775 & & & \\
\hline \multirow[t]{2}{*}{ 13. Individual Tax at Intelligent } & 1 & 16 & 1.188 & 1.642 & 2.117 & 29 & .043 \\
\hline & 2 & 15 & .200 & 0.775 & & & \\
\hline \multirow[t]{2}{*}{ 14. Transportation at Interactive } & 1 & 16 & 2.063 & 1.569 & 2.740 & 29 & .010 \\
\hline & 2 & 15 & .667 & 1.234 & & & \\
\hline \multirow[t]{2}{*}{ Transportation at Transaction } & 1 & 16 & 1.750 & 1.612 & 2.992 & 29 & .006 \\
\hline & 2 & 15 & .333 & 0.900 & & & \\
\hline \multirow[t]{2}{*}{ Transportation at Intelligent } & 1 & 16 & 1.000 & 1.549 & 2.060 & 29 & .048 \\
\hline & 2 & 15 & .133 & 0.516 & & & \\
\hline
\end{tabular}

\section{DISCUSSION AND CONCLUSIONS}

First, most of eG2C links were convenient for citizens to identify when they visit Chinese province e-government sites. When users clicked on eG2C links, the majority of the eG2C main pages had a loading speed of around one second and presented within approximately one screen per page length. The graphic illustrations on the eG2C main pages were primarily local historical attractions, sceneries, and province logos. To facilitate government transparency and citizens' use of e-government services, most of the province eG2C sites provided the following 19 services online: birth planning and adoption, employment, healthcare, citizenship registration, marriage license, education, customs and immigration, social security, housing, transportation, culture and religion, passport and licenses, public and postal services, individual tax and reporting, death and funeral, military service, legal service, travel, and disability. As research shows, Web visitors form their first impressions of a Web site within just the first few seconds of clicking on for deciding whether to quit the site or not [e.g., 1, 12]. Therefore, Web design principles require the appropriate page screen length of 1-2 screens for viewing convenience, the proper use of graphics and text for visual attractiveness and page loading speed, and adequate number of service links for user convenience. Obviously, the Chinese province eG2C sites' user-interface characteristics are in line with the Web design principles. These user-interface characteristics appeared to influence positively the online experience of the interviewees of the study, as they reported being overall pleased with the growth of China's e-government services.

However, while many popular social media were available and also were widely used by people in China, only nine of the 31 province eG2C sites offered Weibo, a Chinese Twitter-like tool, although most of the 31 eG2C sites did provide other related communication tools such as email, report fraud box, and suggestion/complaint box. 
Obviously, the nine province eG2C sites that were offering Weibo serve as a good example for other province eG2C sites to follow. In addition, to genuinely promote public participation, the 31 province eG2C sites need to include more social media tools such as Ren Ren ( 1 人 ( YOURU 优酷 ), which were widely used by people in China.

Second, most of the province eG2C sites provided the following eight services with a range of informational, interactive, transactional, or intelligent capacities: (a) birth planning and adoption, (b) employment, (c) healthcare, (d) citizenship registration, (e) marriage license, (f) education, (g) customs and immigration, and (h) social security. However, the findings identified some areas that need improvement. For example, while all these services were at effective information and interactive capacities, only a minority of them were at the transactional phase allowing users to do business online such as filing tax documents, renewing licenses, and bidding contracts and at the advanced intelligent phase enabling citizens to create their accounts and personalize the site contents and services. As interviewees pointed out, the eG2C services with transactional and intelligent capacities greatly enabled citizens to conveniently and effectively communicate and do business with government and participate in government decisions. Therefore, more eG2C services need to move to the advanced transactional and intelligent phases.

Finally, significant differences existed between affluent provinces and less affluent ones in many eG2C services at the interactive, transactional, and intelligent phases. The affluent provinces offered the eG2C services at significantly more advanced levels than did the less affluent provinces. This finding is consistent with Wilkinson and Cappel's research result [10] that economically affluent counties offered better e-government sites than did the less affluent ones. Therefore, the Chinese central government needs find ways to assist the less-affluent provinces in improving their eG2C services in order to build China into a powerful networked country [11]. The less-affluent provinces also need to realize the importance of eG2C services in the Internet Age and allocate more resources for the eG2C improvement.

\section{RECOMMENDATION FOR FURTHER RESEARCH}

This study assessed the impact of Chinese province eG2C services on government transparency and citizens' participation. A further study is recommended to investigate how Chinese province e-government-to-business (eG2B) services affect (a) companies' business operations, competitiveness, and growth; and (b) provinces' economy growth and prosperity.

\section{REFERENCES}

1. Awad, E. M. (2004). Electronic commerce: From vision to fulfillment. Upper Saddle River, NJ: Prentice Hall.

2. Boggs, R. A., \& Walters, D. (2006). A longitudinal look at e-government in practice. Issues in Information Systems, 7(2), 161-164.

3. Campbell, D. \& Beck, A. C. (2004). Answering allegations: The use of the corporate website for restorative ethical and social disclosure. Business Ethics, 13(2), 100.

4. Chen, Z. Z. (2013, September 23). Internet-based report fraud box at China Ministry of Supervision web site received more than 760 reports daily over 20 days since the start of the reporting service. China Discipline Inspection and Supervision Report. Available: http://www.ccdi.gov.cn/xwyw/201309/t20130923_10575.html

5. China National Statistics Bureau. (2013, December 31). Statistical report of 2012 annual regional development and life index (DLI). Available: http://www.stats.gov.cn/tjsj/zxfb/201312/t20131231_492765.html

6. CNNIIC. (2014, January 16). The statistical report of China Internet network development status. Available: http://www.cnnic.net.cn/hlwfzyj/hlwxzbg/hlwtjbg/201401/t20140116_43820.htm

7. Cochran, W. G. (1977). Sampling techniques ( $3^{\text {rd }}$ ed.). New York: John Wiley and Sons.

8. King, G., Pan, J., \& Roberts, M. E. (2013). How censorship in China allows government criticism but silences collective expression. American Political Science Review, 107(2), 326-343.

9. Sunstein, C. R. (2010, April 7). The social media, web-based interactive technologies, and the paperwork reduction Act. Executive Office of the President of U.S.A. Available: http://www.whitehouse.gov/sites/default/files/omb/assets/inforeg/SocialMediaGuidance_04072010.pdf

10. Wilkinson, V. O. \& Cappel, J. J. (2005). Impact of economic prosperity and population on e-government involvement. Issues in Information Systems, (6), 204-209. 
11. Xinhua News. (2014, February 27). The Chinese President Xi Jinping chaired the first meeting of China's Central Network Security and Informatization Leading Group. Available:http://www.gov.cn/ldhd/201402/27/content_2625036.htm

12. Zhao, J. J. (2003). Web design and development for e-business. Upper Saddle River, NJ: Prentice Hall.

13. Zhao, J. J. \& Zhao, S. Y. (2004). Internet technologies used by INC. 500 Corporate Web Sites, Issues in Information Systems, (4), 366-372.

14. Zhao, J. J., Truell, A. D., \& Alexander, M. W. (2006). User-interface design characteristics of Fortune 500 B2C e-commerce sites and industry differences. The Delta Pi Epsilon Journal, 48(1), 43-55. 